\title{
Flavonoid Profiles of Two New Approved Romanian Ocimum Hybrids
}

\author{
Fanica Balanescu ${ }^{1,2}$, Maria Daniela Ionica Mihaila ${ }^{1}$, Geta Cârâc ${ }^{1}$, Bianca Furdui ${ }^{1, *(0)}$, \\ Costel Vînătoru ${ }^{3}$, Sorin Marius Avramescu ${ }^{4,5}$, Elena Lacramioara Lisa ${ }^{2}$, \\ Mihaela Cudalbeanu ${ }^{1,6, *}$ and Rodica Mihaela Dinica ${ }^{1, * \mathbb{D}}$ \\ 1 Faculty of Sciences and Environment, Department of Chemistry Physical and Environment, \\ "Dunarea de Jos" University of Galati, 111 Domneasca Street, 800201 Galati, Romania; \\ fanica.balanescu@ugal.ro (F.B.); ionicamariadaniela@gmail.com (M.D.I.M.); geta.carac@ugal.ro (G.C.) \\ 2 Faculty of Medicine and Pharmacy, “Dunarea de Jos" University of Galati, 35 Al. I. Cuza Street, \\ 800010 Galati, Romania; elena.lisa@ugal.ro \\ 3 Vegetable Research and Development Station Buzău, 23 Mesteacănului Street, 120024 Buzau, Romania; \\ costel_vinatoru@yahoo.com \\ 4 Faculty of Chemistry, Department of Organic Chemistry, Biochemistry and Catalysis, \\ University of Bucharest, 90-92 Soseaua Panduri, 050663 Bucharest, Romania; sorin_avramescu@yahoo.com \\ 5 University of Agronomic Science and Veterinary Medicine, 59 Marasti Blvd, 011464 Bucharest, Romania \\ 6 National Institute for Research and Development in Environmental Protection-INCDPM, \\ 294 Splaiul Independentei, 060031 Bucharest, Romania \\ * Correspondence: bfurdui@ugal.ro or bianca.furdui@ugal.ro (B.F.); mihaelacudalbeanu@gmail.com (M.C.); \\ rodinica@ugal.ro or rodica.dinica@ugal.ro (R.M.D.)
}

Academic Editor: Maria Atanassova

Received: 7 September 2020; Accepted: 3 October 2020; Published: 7 October 2020

\begin{abstract}
Basil (Ocimum spp.) is a traditional herbal medicine abundant in antioxidants such as phenolic compounds. As part of a diet, this herb is proved to have some roles in decreasing the risk of cancer, and in the treatment of inflammation and neurodegenerative diseases. This study aims to explore the total phenolic and flavonoid content of two new basil hybrids growing in Romania, namely "Aromat de Buzau" (AB) and "Macedon" (MB). The antioxidant capacity of those two species was also analyzed by DPPH and cyclic voltammetry. Six different flavonoids, such as catechin (+), rutin, hyperoside, naringin, naringenin, and genistein, were separated, identified, and quantified by HPLC-DAD chromatography, for the first time, from romanian basil hybrids. The main flavonoid of the extracts was found to be naringin which is present in the highest amount $(26.18 \mathrm{mg} / \mathrm{kg}) \mathrm{in}$ "Aromat de Buzau" (O. basilicum) methanolic extract. These results suggest that dietary intake of these new hybrids can be a source of antioxidant compounds.
\end{abstract}

Keywords: flavonoids; HPLC-DAD quantification; antioxidant activity; cyclic voltammetry; Romanian Ocimum hybrids

\section{Introduction}

To prevent the radical chain of oxidation reactions, antioxidants are often added to foods, acting by inhibiting the beginning and multiplication steps, leading to the close of the reaction and the delay of the oxidation process. Finding natural antioxidants to replace synthetic compounds because of safety concerns and the increase of consumer's preferences for natural antioxidants is one of the main concerns of the food industry [1,2].

There is strong evidence that oxidative stress is caused by an imbalance between prooxidants and antioxidants. The reactive species, such as reactive oxygen species (ROS), nitrogen species (RNS), or electrophilic species (RES), and the cells antioxidative defense systems, play a central role in the 
pathogenesis of several diseases, including neurodegenerative diseases, kidney diseases, and diabetes, cancers, or cardiovascular diseases. To counteract this stress, the nuclear factor erythroid 2-related factor 2 (Nrf2) plays a major role in reducing oxidative damage through a series of small antioxidant molecules and maintaining intracellular redox homeostasis [3-7].

The most important natural antioxidants with important biological activities are polyphenols, compounds that have attracted the interest of researchers for the prevention and treatment of various diseases [8,9]. Flavonoids are a family of polyphenolic plant metabolites [10] having various functions in plants, acting as antimicrobial agents, as plant protection photoreceptors, and UV protectors, but they are also responsible for a range of pharmacological properties, including antioxidant, antiallergic, anti-inflammatory, antimicrobial, anti-viral, antithrombotic, or antioncogenic activities [11-13]. The biological activity of flavonoids depends on their structural class, the degree of hydroxylation, substitutions and conjugations, and on the degree of polymerization [13,14].

Many flavonoidic compounds, such as rutin, naringin, naringenin, or genistein, have been reported to have physiologic benefits, including inhibition of tumor angiogenesis, protection from cardiovascular disease, promotion of neural protection, anti-angiogenic activities in inflammatory, chronic, and metabolic diseases [15,16], and nitric oxide scavenging activity [10]. Many of these benefits coming from their special antioxidant and free radical inhibition properties [17].

The Ocimum genus belongs to the Lamiaceae family that contains over 150 cultivated aromatic perennial herb species, spread all over tropical and temperate regions, used in diet and to treat different types of diseases [2,18-20]. Ocimum basilicum (O. basilicum) is popularly known as sweet basil and has been reported in many fields, e.g., agriculture, food, ornamental, religious, and pharmacology, due to its volatile aromatic compounds [19-21]. Ocimum citriodorum (O. citriodorum), a natural hybrid between sweet basil (O. basilicum) and African basil (O. americanum), is known as lemon basil due to the specific strong aroma of lemon and is often used in the Mediterranean and Asian cuisines because of its odor and flavor, and also used as a raw material for the chemical, pharmaceutical, and food industries [20,22].

Basil was brought to Europe long time ago by Alexander the Great [20]. Since 1996, various hybrids of basil were acclimatized in Buzau, Romania [20]. Due to their beneficial healthy effects, the consumption of culinary herbs has increased worldwide, so the knowledge of new polyphenol-rich herbs is of increasing interest. We report here, for the first time, the evaluation of alcoholic extracts of two basil hybrids from Romanian cultivars: "Aromat de Buzau" (O. basilicum) and "Macedon" (O. citriodorum) from the point of view of polyphenol and flavonoid compounds. Therefore, we explored the antioxidant potential of Romanian basil hybrids by developing methods for HPLC-DAD flavonoid quantifications, and for antioxidant capacity evaluation through free radical inhibitory activity and cyclic voltammetry.

\section{Results}

\subsection{Phytochemical Characterization of the Romanian Varieties of Basil}

The goal of the present research was the quantification of biological compounds such as phenolic acid and flavonoid and the evaluation of the antioxidant effects of two Romanian basil hybrids extracts. The diversity and the content of phenolic acids and flavonoids were determined for methanolic and ethanolic extracts of two Romania Ocimum hybrids, "Aromat de Buzau" and "Macedon", respectively (Figure 1), by developing also an HPLC-DAD method. 


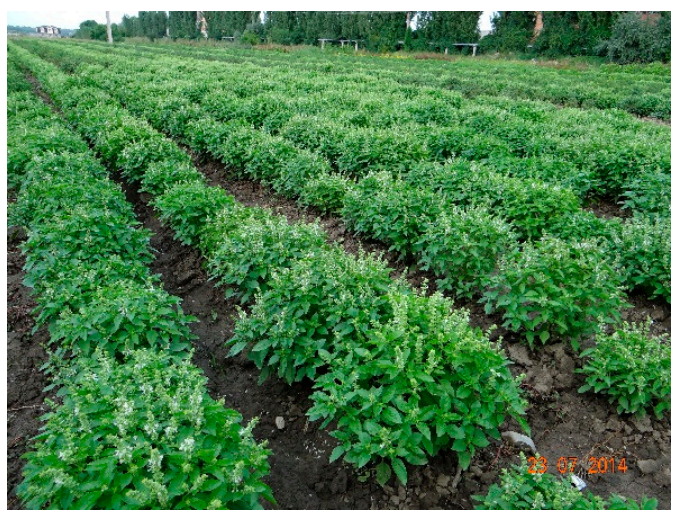

(a)

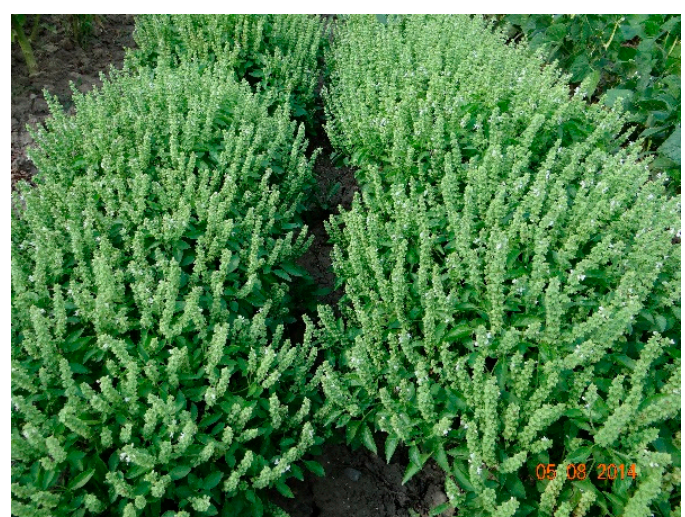

(b)

Figure 1. O. basilicum hybrids: "Aromat de Buzau" (a) “Macedon" (b).

\subsubsection{Polyphenolic Acid Content}

The total phenolic acids based on the Folin-Ciocalteu micromethod were determined for ethanolic and methanolic extracts of Ocimum hybrids [23], and this led to the results which are presented in Figure 2a.

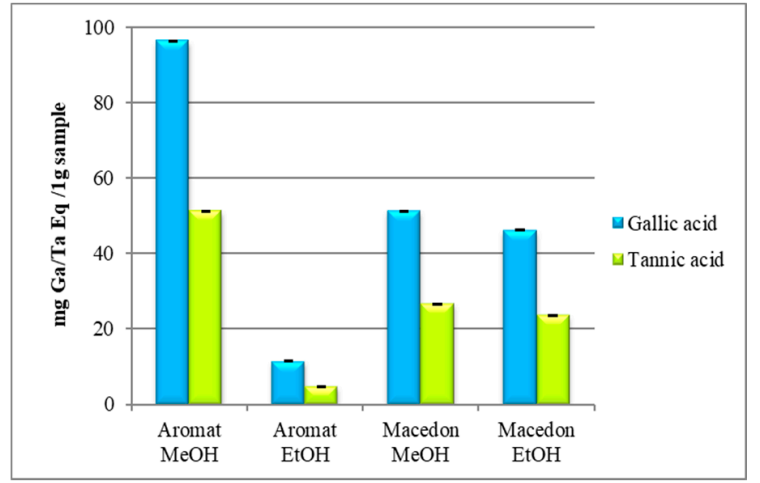

(a)

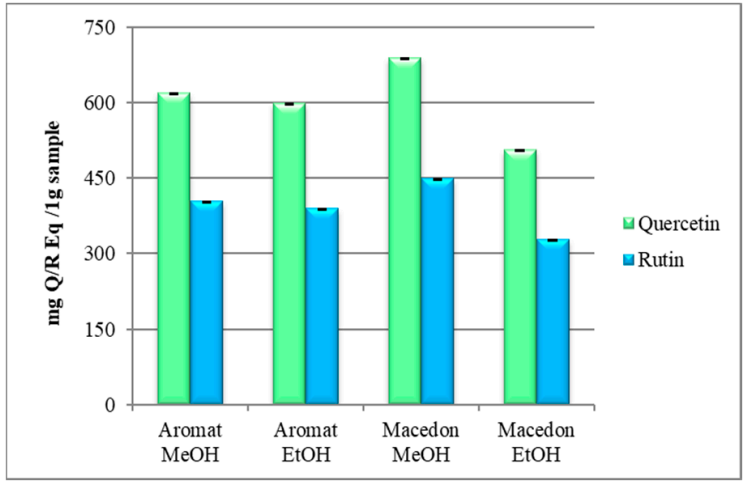

(b)

Figure 2. The total content of the phenolic acids (a) and flavonoids (b) extracted from "Aromat de Buzau" (O. basilicum) and "Macedon" (O. citriodorum) extracts. The results were expressed in equivalents of gallic acid and tannic acid per $1 \mathrm{~g}$ sample, and quercetin and rutin per $1 \mathrm{~g}$ sample, respectively.

\subsubsection{Flavonoid Content}

The same solvents, methanol and ethanol, were also used for the evaluation of the extraction efficiency of flavonoids, expressed as quercetin $(\mathrm{Q})$ and rutin $(\mathrm{R})$. The results of the four basil extracts showed a higher amount of the total flavonoid contents than phenolic acids contents. Some variations were observed according to the plant species and the extraction solvents used (Figure 2b).

\subsection{Antioxidant Potentials of the Romanian Varieties of Basil}

To explore the relation between the composition of extracts of antioxidant compounds and their antioxidant capacities, two different techniques (DPPH assay and cyclic voltammetry) were used.

\subsubsection{DPPH Assay}

Polyphenol compounds of the plant origin have been shown to exert antioxidant effects [24]. Any compound, in low concentrations compared with those of an oxidizable substrate which presents significantly delays or prevents oxidation of the substrate is an antioxidant [25]. DPPH is a violet stable free radical which interacts with antioxidant compounds, and through an electrons-proton transfer 
process it is inactivated and changes its color from violet to yellow [24]. By increasing the concentration of phenolic compounds and the degree of hydroxylation of the phenolic compounds, their DPPH radical scavenging activity also increases and can be defined as antioxidant activity [24].

Different concentrations of basil methanolic and ethanolic extracts, between 0.0048 and $2.5 \mathrm{mg} / \mathrm{mL}$ were used for the antioxidant DPPH assays and their $\mathrm{IC}_{50}$ values are presented (Figures 3 and 4).

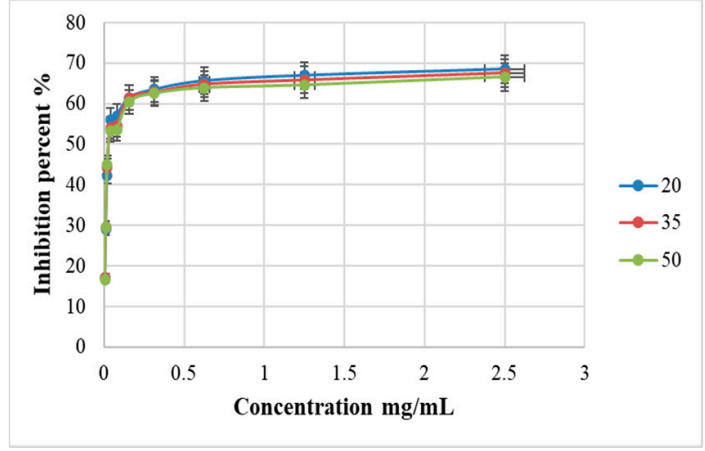

(a)

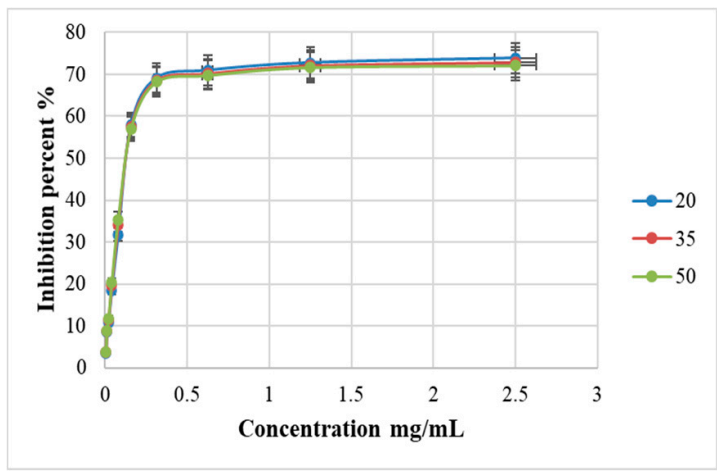

(c)

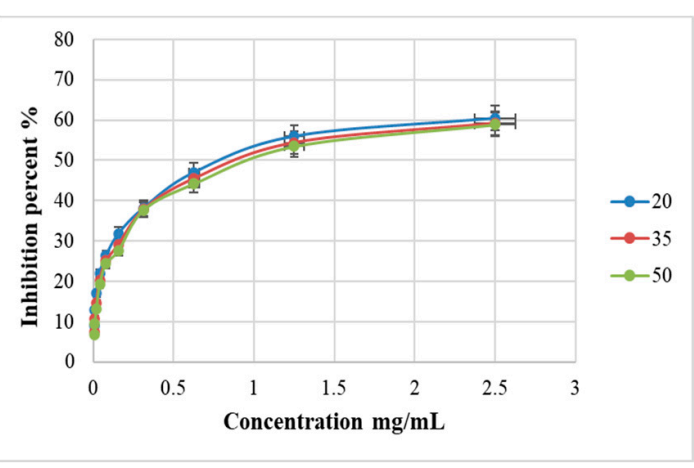

(b)

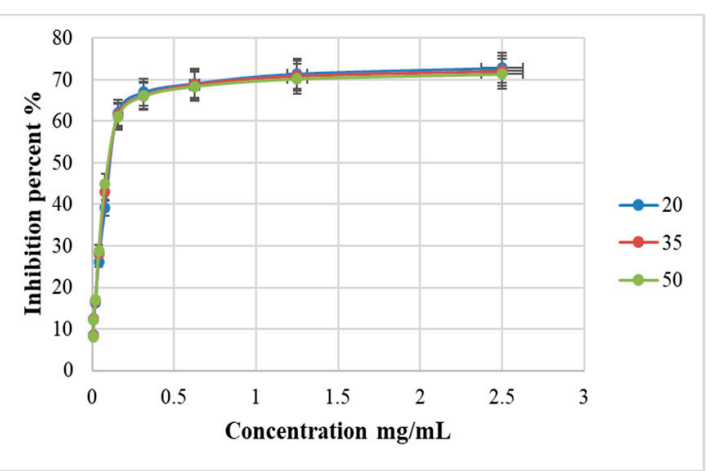

(d)

Figure 3. The DPPH inhibition percent of the (a) O. basilicum ("Aromat de Buzau") methanolic extract, (b) O. basilicum ("Aromat de Buzau") ethanolic extract, (c) O. citriodorum ("Macedon") methanolic extract, and (d) O. citriodorum ("Macedon") ethanolic extract after 20 (blue), 35 (red) and 50 (green) minutes of incubation.

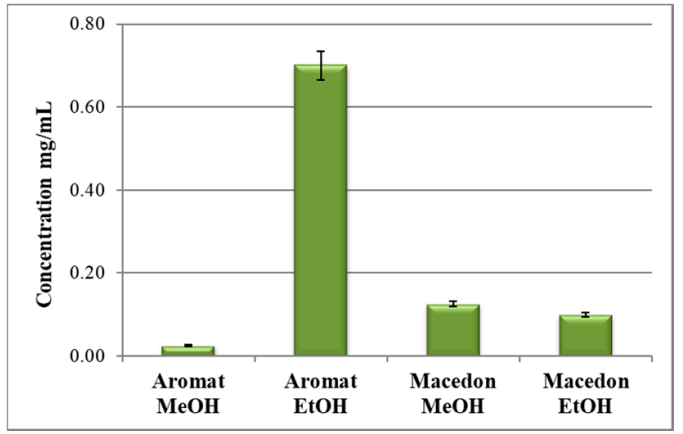

(a)

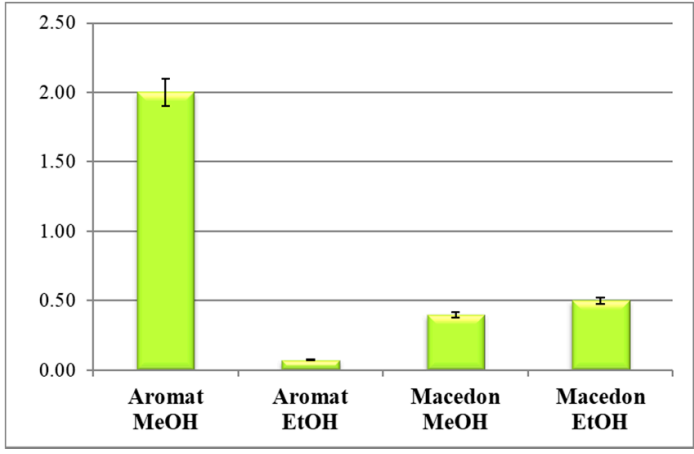

(b)

Figure 4. The $\mathrm{IC}_{50}$ values (a) and antioxidant capacity index (b) of the basil extracts.

\subsubsection{Electrochemical Evaluation of Antioxidant Capacity by Cyclic Voltammetry}

The recorded OCV (open circuit voltage) of the extracts from both basil hybrids show a stable potential at $30 \mathrm{~min}$ with a slow difference in the values of potential between used solvents (Figure 5I). A more positive potential $\left(0.115 \mathrm{~V} / \mathrm{Ag} / \mathrm{AgCl}_{\text {sat }}\right)$ was determined for the $\mathrm{AB}$ ("Aromat de Buzau") methanolic 
extracts, than for the MB ("Macedon") methanolic extracts (0.095 V/Ag/AgCl $\mathrm{sat}_{\text {st }}$ ). The potential of the ethanolic extracts was around of $80 \mathrm{mV} / \mathrm{Ag} / \mathrm{AgCl}_{\text {sat }}$ and there were no significant differences between the basil samples.

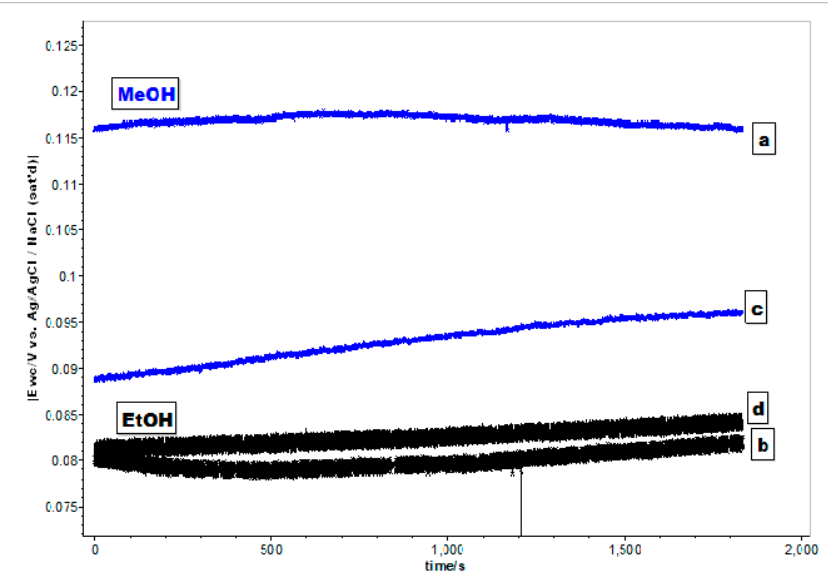

(I)

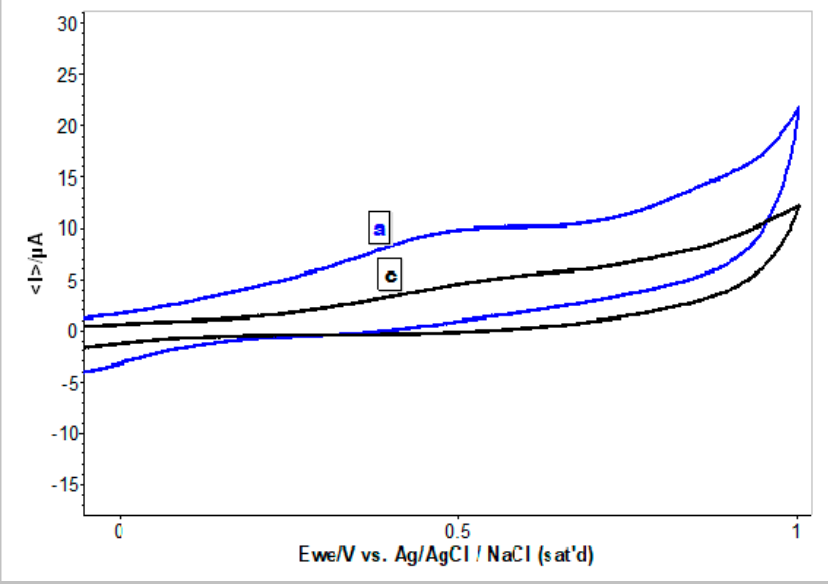

(II)

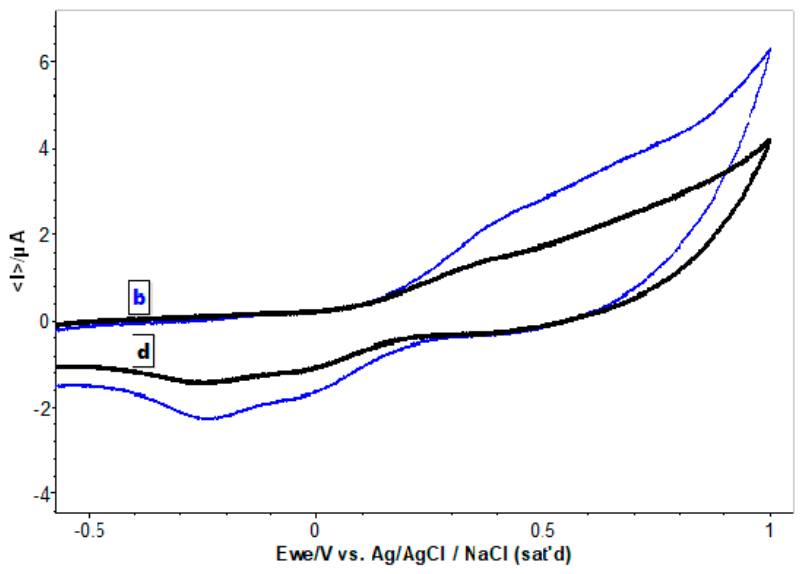

(III)

Figure 5. (I) OCV registered for basil methanolic extracts of $\mathrm{AB}$ (a) and $\mathrm{MB}$ (c) and, respectively for ethanolic extracts of $\mathrm{AB}(\mathbf{b})$ and $\mathrm{MB}(\mathbf{d})$. (II) Cyclic voltammograms recorded for basil methanolic extracts of $\mathrm{AB}$ (a-blue) and $\mathrm{MB}$ (c-black), $\mathrm{E}= \pm 1 \mathrm{~V} / \mathrm{Ag} / \mathrm{Ag} \mathrm{Cl} \mathrm{Cl}_{\text {sat }}$, at $100 \mathrm{mVs}^{-1}$. (III) Cyclic voltammograms recorded for basil ethanolic extracts of $\mathrm{AB}$ (c-blue) and $\mathrm{MB}$ (d-black), $\mathrm{E}= \pm 1 \mathrm{~V} / \mathrm{Ag} / \mathrm{Ag}$ Clsat, at $100 \mathrm{mVs}^{-1}$. 
Figure 5II,III shows the cyclic voltammograms of all basil samples and it is obvious that the voltammogram profiles of two hybrid species are different. In the O. basilicum ("Aromat de Buzau") methanolic extract, around $0.5 \mathrm{~V} / \mathrm{Ag} / \mathrm{AgClsat}$ are biocompounds with potential intensity activity of $\mathrm{I}_{\mathrm{a}}$ $60 \mu \mathrm{A}$, with circa 50\% more active than in the O. citriodorum ("Macedon") methanolic extract. In the ethanolic extracts, even the intensity activity is less than in methanolic AB ("Aromat de Buzau") extract compared with the MB ("Macedon") extract showing a larger band for the electronic changes starting from $0.25 \mathrm{~V} / \mathrm{Ag} / \mathrm{AgCl}_{\text {sat }}$ till $0.80 \mathrm{~V} / \mathrm{Ag} / \mathrm{AgCl}_{\text {sat }}$ (Figure $5 \mathrm{III}$ ).

The CV's recorded for basil hybrid extracts after $24 \mathrm{~h}$ indicated an increase in the Ia current values. For the both methanol extracts, the current also indicates a decreased use of values when the experiment cycle is repeated, which suggests that, the active compounds are still in the samples (Figure 6) [26].

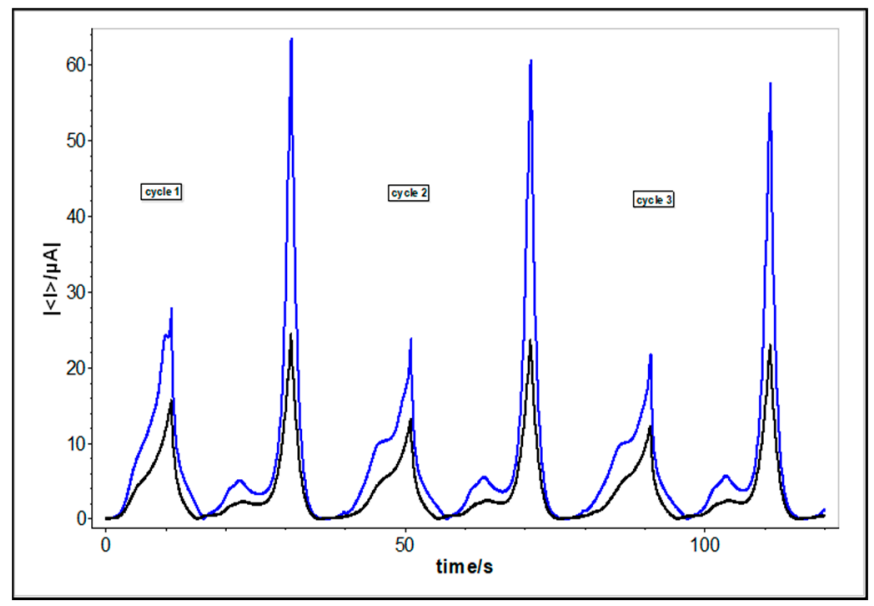

Figure 6. Evolution of current vs time in cyclic voltammograms recorded for basil methanolic extracts of $\mathrm{AB}$ (blue) and $\mathrm{MB}$ (black), $\mathrm{E}= \pm 1 \mathrm{~V} / \mathrm{Ag} / \mathrm{Ag} \mathrm{Cl}_{\text {sat }}$, at $100 \mathrm{mVs}^{-1} ; 3$ cycles.

Figure 7 shows that the UV bands of basil extracts before and after CV analysis overlap. The characteristic wavelengths of each UV-Vis spectrum proved the presence of flavonoidic compounds in the analyzed extracts. The presence of naringin in the Romanian basil hybrid extracts was confirmed by HPLC-DAD quantification using naringin as standard and it was observed in both Romanian basil varieties, with a $\lambda_{\max }$ at $228 \mathrm{~nm}$ and other characteristic signals in the range of $250 \sim 320 \mathrm{~nm}[27,28]$.

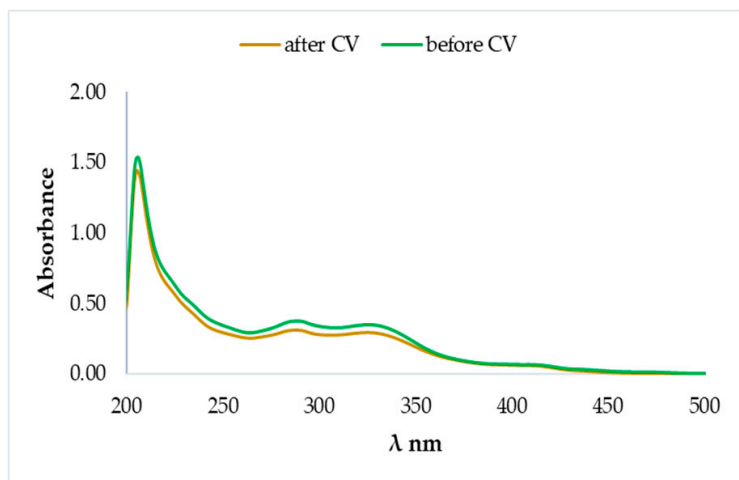

(a)

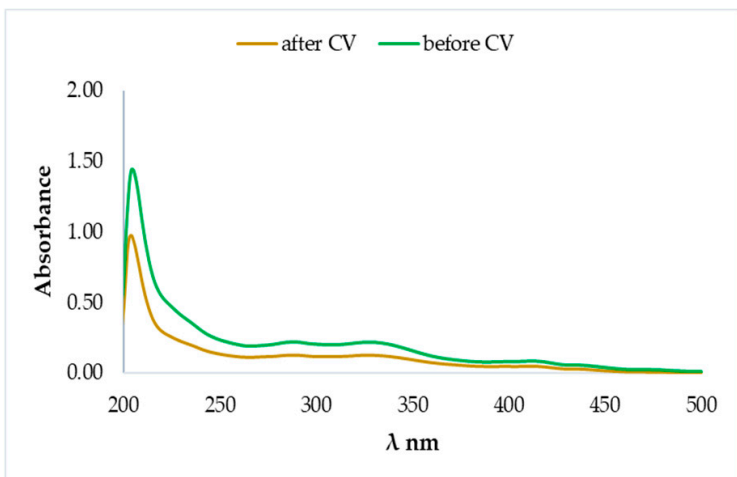

(b)

Figure 7. Cont. 


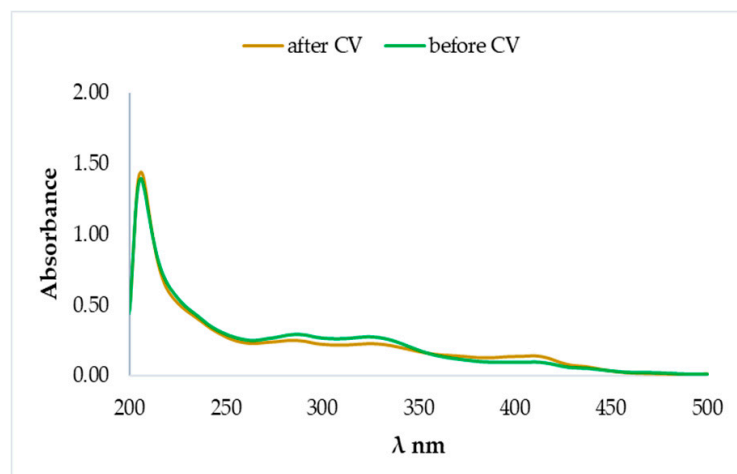

(c)

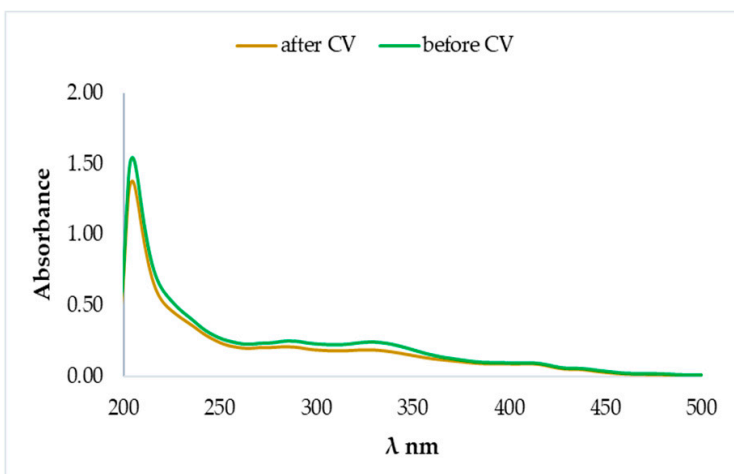

(d)

Figure 7. UV-VIS spectra recorded for the samples before and after cyclic voltammetry experiments: "Aromat de Buzau" methanolic extract (a) and ethanolic extract (b), "Macedon" methanolic extract (c) and ethanolic extract (d).

\subsection{HPLC-DAD Separation, Identification and Quantification of Flavonoid Compounds}

To analyze the major contributors on the antioxidant activity of our plant matrices, HPLC-DAD analysis was performed. Several studies of Ocimum species have described the presence of bioactive compounds in different plant parts extracts [29]. In this research, the analysis of the secondary metabolites from flavonoid class was made quantitatively using an original the HPLC-DAD method. Generally, flavonoids have many roles and functions, their protective effects including anti-inflammatory, antioxidant, antiviral, and anti-carcinogenic properties [30,31].

The chromatographic separation, using reference compounds, revealed the presence in the Romanian basil extracts of six flavonoids, namely catechin (+), rutin, hyperoside, naringin, naringenin, and genistein (Figure 8). Other peaks could not be identified due to a lack of standards. The flavonoid quantification of the four methanolic and ethanolic basil extracts of the two different Romanian Ocimum hybrids are summarized in Table 1. The results showed that the naringin is the principal compound of basil extracts ranged from $9.30 \pm 0.15$ to $26.18 \pm 0.23 \mathrm{mg} / \mathrm{kg}$ dry plant. The best quantities of naringin were recorded for both methanolic extract of basil hybrids, the concentration being three times higher in O. basilicum variety "Aromat de Buzau".

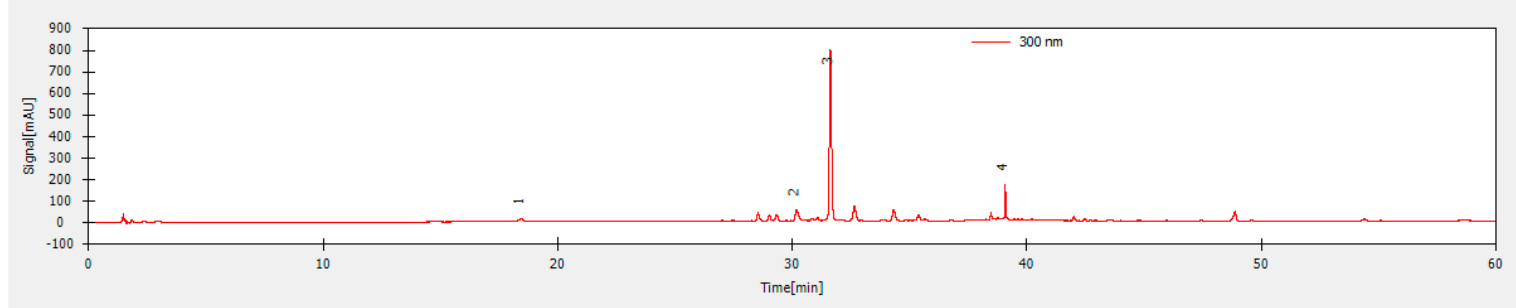

(a)

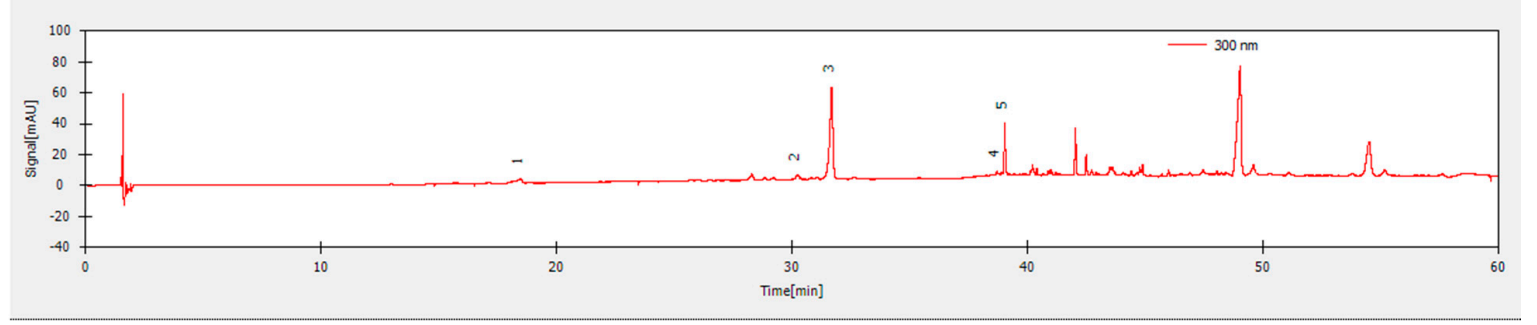

(b)

Figure 8. Cont. 


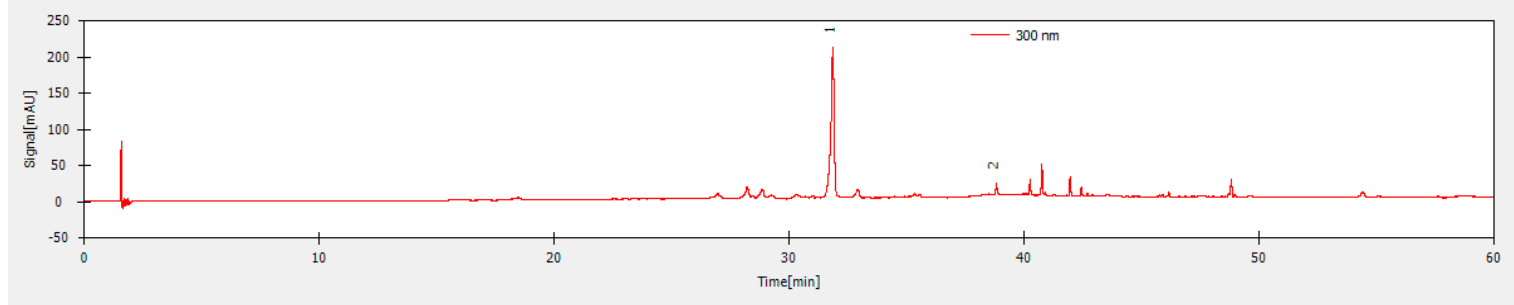

(c)

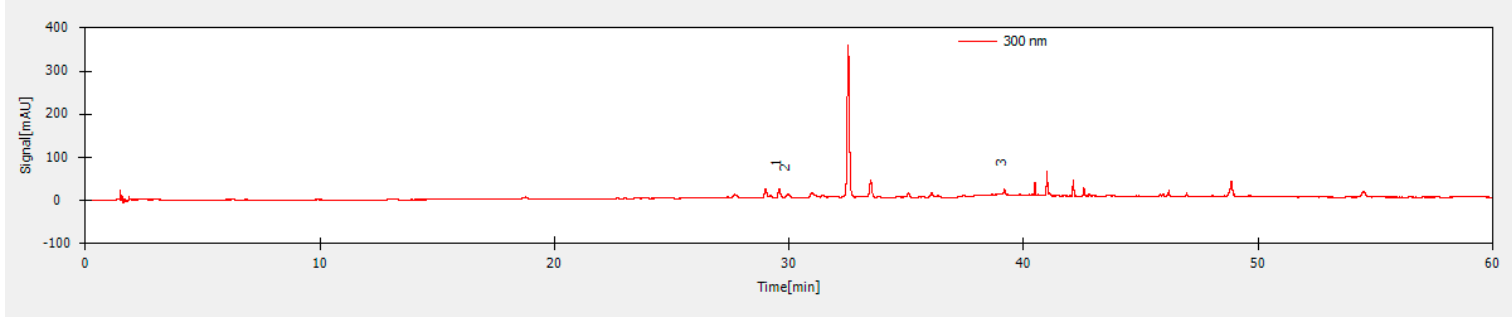

(d)

Figure 8. HPLC-DAD chromatograms of the samples: (a) "Aromat de Buzau" -methanolic extract (1-catechin, 2-rutin, 3-naringin, 4-genistein), (b) "Aromat de Buzau" ethanolic extract (1—catechin, 2-rutin, 3-naringin, 4-naringenin, 5-genistein), (c) "Macedon" methanolic extract (1-naringin, 2-naringenin), and (d) "Macedon" ethanolic extract (1-rutin, 2-hyperoside, 3-genistein) with detection at $300 \mathrm{~nm}$.

Table 1. HPLC-DAD identification and quantification of flavonoids from basil extracts.

\begin{tabular}{cccccc}
\hline $\begin{array}{c}\text { Compound } \\
(\mathbf{m g} / \mathbf{k g})\end{array}$ & $\begin{array}{c}\text { TR } \\
(\mathbf{m i n})\end{array}$ & $\begin{array}{c}\text { Aromat } \\
\mathbf{M e O H}\end{array}$ & $\begin{array}{c}\text { Aromat } \\
\text { EtOH }\end{array}$ & $\begin{array}{c}\text { Macedon } \\
\mathbf{M e O H}\end{array}$ & $\begin{array}{c}\text { Macedon } \\
\text { EtOH }\end{array}$ \\
\hline Catechin $(+)$ & 19.50 & $0.13 \pm 0.01$ & $0.23 \pm 0.01$ & - & - \\
Rutin & 29.78 & $0.78 \pm 0.02$ & $0.13 \pm 0.01$ & - & $0.31 \pm 0.01$ \\
Hyperoside & 29.98 & - & - & - & $0.20 \pm 0.01$ \\
Naringin & 31.50 & $26.18 \pm 0.23$ & $2.24 \pm 0.09$ & $9.30 \pm 0.15$ & - \\
Naringenin & 38.78 & - & $0.15 \pm 0.01$ & $0.17 \pm 0.01$ & - \\
Genistein & 39.10 & $0.50 \pm 0.01$ & $0.16 \pm 0.01$ & - & $0.17 \pm 0.01$ \\
\hline
\end{tabular}

* Retention time (TR) error of mean for compounds was $\pm 0.0001-0.2$ min.-unidentified.

\section{Disscusion}

The analyzed extracts of Romanian Ocimum hybrids were prepared by ultrasound solvent extraction which favors cell wall disruption and greater solvent penetration into the cells, accelerating the extraction.

\subsection{Phytochemical Characterization of the Romanian Varieties of Basil}

The extraction efficiency of polyphenols was evaluated for two different solvents, ethanol and methanol, based on total phenolic acids content expressed as gallic acid (GA) and tannic acid (Ta). The results revealed that, from the four basil extracts, the methanolic extract of "Aromat de Buzau" contain the highest quantity of phenolic compounds $(96.32 \pm 0.23 \mathrm{mg} \mathrm{GaEq} / 1 \mathrm{~g}$ sample and $51.16 \pm 0.19 \mathrm{mg} \mathrm{TaEq} / 1 \mathrm{~g}$ sample, respectively) while the ethanolic extract of same hybrid contain the lower quantity of phenolic compounds (11.47 $\pm 0.12 \mathrm{mg} \mathrm{GaEq} / 1 \mathrm{~g}$ sample and $4.78 \pm 0.05 \mathrm{mg} \mathrm{TaEq} / 1 \mathrm{~g}$ sample, respectively) (Figure 2a). By comparison, the phenolic acids present in the "Macedon" extracts showed a lower content than "Aromat de Buzau" methanolic extract, but higher contents than "Aromat de Buzau" ethanolic extract (51.24 $\pm 0.42 \mathrm{mg} \mathrm{GaEq} / 1 \mathrm{~g}$ sample and $26.51 \pm 0.10 \mathrm{mg}$ TaEq/1g sample, respectively for "Macedon" methanolic extract and $46.13 \pm 0.31 \mathrm{mg} \mathrm{GaEq} / 1 \mathrm{~g}$ sample and $23.72 \pm 0.12 \mathrm{mg} \mathrm{TaEq} / 1 \mathrm{~g}$ sample, respectively for "Macedon" ethanolic extract). 
The results of the four basil extracts showed a higher amount of the total flavonoid contents than phenolic acids contents. Some variations were observed according to the plant species and the extraction solvents used (Figure 1b). "Aromat de Buzau" (O. basilicum) methanolic extract presents a flavonoid amount of $619.34 \pm 4.98 \mathrm{mg}$ QEq/1g sample and $402.43 \pm 3.06 \mathrm{mg} \mathrm{REq} / 1 \mathrm{~g}$ sample, while the ethanolic extract contains $598.78 \pm 2.63 \mathrm{mg}$ QEq/1g sample and $388.91 \pm 2.98 \mathrm{mg} \mathrm{REq} / 1 \mathrm{~g}$ sample, respectively. The total flavonoid amount of "Macedon" (O. citriodorum) methanolic extract was found to be $689.05 \pm 5.78 \mathrm{mg}$ QEq/1g sample and $448.18 \pm 3.05 \mathrm{mg} \mathrm{REq} / 1 \mathrm{~g}$ sample while the contents of flavonoids for "Macedon" (O. citriodorum) ethanolic extract expressed as quercetin was $505.20 \pm 3.34 \mathrm{mg} Q E q / 1 \mathrm{~g}$ sample and expressed as rutin was $327.50 \pm 2.87 \mathrm{mg} \mathrm{REq} / 1 \mathrm{~g}$ sample.

\subsection{Antioxidant Potentials of the Romanian Varieties of Basil}

The results obtained by analyzing the Romanian basil hybrid samples showed that the DPPH radical scavenger activity is greatly influenced by the solvent extraction and the phytochemical composition (Figure 2). The antioxidant capacity of basil species is a useful parameter which correlates with the phytochemical determinations. The O. basilicum ("Aromat de Buzau") methanolic extract showed free radical scavenging activity with an inhibition percent of $68 \pm 0.98 \%$ while the ethanolic extract had a lower inhibition percent of $60 \pm 0.85 \%$. Also, the O. citriodorum ("Macedon") methanolic extract showed a free radical scavenging activity with an inhibition percent of $73 \pm 0.88 \%$ while the ethanolic extract had an inhibition percent of $72 \pm 0.73 \%$.

The DPPH scavenging $\mathrm{IC}_{50}$ values estimated for the Romanian basil hybrid extracts were of $0.025 \pm 0.011 \mathrm{mg} / \mathrm{mL}$ ("Aromat de Buzau" methanolic extract), $0.700 \pm 0.302 \mathrm{mg} / \mathrm{mL}$ ("Aromat de Buzau" ethanolic extract), $0.125 \pm 0.121 \mathrm{mg} / \mathrm{mL}$ ("Macedon" methanolic extract), and respectively of $0.100 \pm 0.097 \mathrm{mg} / \mathrm{mL}$ ("Macedon" ethanolic extract). Interestingly, a lower $\mathrm{IC}_{50}$ value shows a higher antioxidant activity in the basil extracts [26]. The highest antioxidant activity was registered for the O. basilicum spp., "Aromat de Buzau" methanolic extract, a result which can be correlated with its high phenolic acid contents (Figure 4a). Our results are in accordance with those from the literature data which showed strong scavenging activity of DPPH radical for the basil methanolic extracts [18]. Figure $4 \mathrm{~b}$ shows the antioxidant activity index (AAI) of the four basil extracts, which is perfectly correlated with the $\mathrm{IC}_{50}$ value presented in Figure $4 \mathrm{a}$.

A moderate antioxidant activity is represented by a value AAI between 0.5 and 1.0, a strong antioxidant activity is when the AAI value is between 1.0 and 2.0, and a very strong activity when AAI $>2.0[23,32]$.

Of the electrochemical methods used for organic antioxidants analysis in foods or medicines, cyclic voltammetry is one of the most used because it is a fast and inexpensive method to detect antioxidants, such as phenols, carotenoids, or vitamins, in samples [33].

The cyclic voltammetry studies demonstrate that the electrochemical oxidation of the basil samples it is strongly related to the structure of the electroactive chemical compounds from the solvent extracts.

The observed electrochemical process supports the good antioxidant activity of Romanian basil extracts which can be attributed to naringin. The naringin oxidative degradation exposed to electrochemical measurements is highlighted in Figure 9.
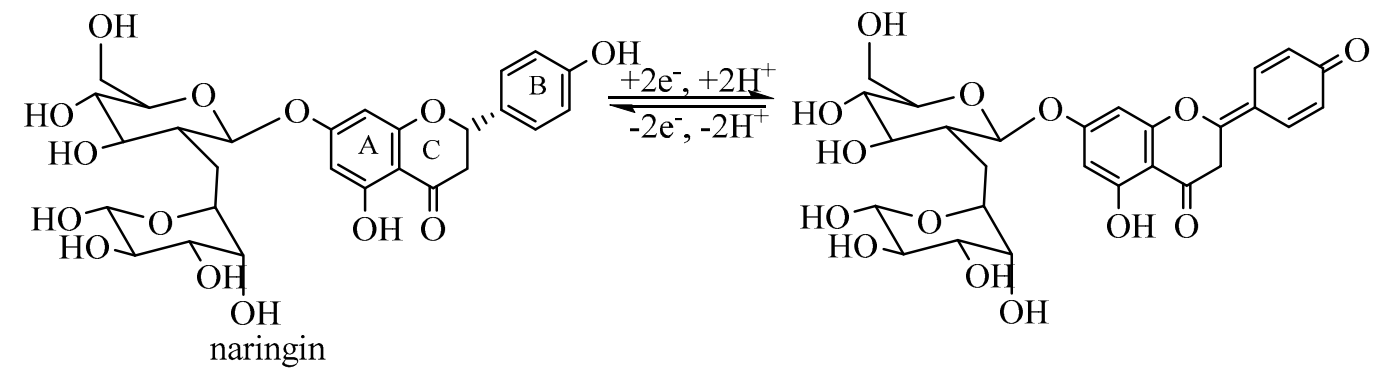

Figure 9. Naringin oxidative degradation. 
The literature data revealed that the conjugation of the ring A with the heterocyclic ring $\mathrm{B}$ and with the unsaturated ring $C$ improves the antioxidant activity of this polyphenolic compounds. Also, the presence of the hydroxyl group in the 3 position of the heterocyclic ring increases the antioxidant activity of flavonoids. Lower antioxidant properties are exhibited by the flavonoid compounds in which no conjugation between the rings $B$ and $C$ is present. [34].

\subsection{HPLC-DAD Separation, Identification and Quantification of Flavonoid Compounds}

The chromatographic separation, using as reference compounds, naringin, naringenin, catechin $(+)$, epicatechin (-), quercetin, hyperoside, rutin, tannic acid, caffeic acid, gallic acid, chlorogenic acid, p-coumaric acid, genistein, and daidzein, revealed the presence in the Romanian basil extracts of flavonoids, such as catechin (+), rutin, hyperoside, naringin, naringenin, and genistein (Figure 8). The flavonoid quantification revealed that the naringin is the principal compound of romanian hybrids basil extracts ranged from $9.30 \pm 0.15$ to $26.18 \pm 0.23 \mathrm{mg} / \mathrm{kg}$ of dry plant. The best quantities of naringin were recorded for both methanolic extract of basil hybrids, the concentration being three times higher in O. basilicum variety "Aromat de Buzau".

The identification of flavonoids argues for the antioxidant activity of basil alcoholic extracts and a proposed mechanism for this could include the following steps:

1. Dissociation of the antioxidant flavonoid ArOH:

$$
\underset{\substack{\mathrm{ArOH} \\ \text { antioxidant }}}{\rightarrow} \underset{\text { aroxyl anion }}{\mathrm{ArO}^{-}}+\mathrm{H}^{+}
$$

2. The electron transfer from the antioxidant anion to the scavenged radical with the formation of the radical anion $\left(\mathrm{R}^{-}\right)$:

$$
\underset{\text { antioxidant anion }}{\mathrm{ArO}^{-}}+\underset{\text { free radical }}{\mathrm{R}^{\cdot}} \rightarrow \mathrm{ArO}^{-}+\underset{\text { radical anion }}{\mathrm{R}^{-}}
$$

3. Radical anion protonation:

$$
\underset{\text { radical anion }}{\mathrm{R}^{-}}+\mathrm{H}^{+} \rightarrow \mathrm{RH}
$$

In the above-mentioned mechanisms, the hydroxyl group of flavonoids stabilize the ROS (reactive oxygen species), and the ionization degree of a polyphenolic antioxidant ( $\mathrm{ArOH})$ depends on characteristic properties of the solvent and their relative ability to solvate and stabilize antioxidant anions. The diversity of these polyphenolic secondary metabolites at the level of each species gives it a different antioxidant activity.

Recently, many studies suggest that an essential role in the defense against oxidative stress, at cellular level, plays the Nrf2, nuclear factor erythroid 2-related factor 2, it activates under various stress conditions, such as exposure to reactive oxygen species or electrophilic stress. For example, genistein, naringenin, and epigallocatechin gallate can induce Nrf2 expression in human breast carcinoma, Caco-2, or endothelial cells and protect them from oxidant injury $[3,4,17,35,36]$ and it exhibits anti-oxidant, anti-mutagenic, and anti-carcinogenic effects [37,38].

At the cellular level, in the cytoplasm, normally, Keap1 (Kelch-like ECH-associated protein 1) is retained and bound to Nrf2. Under conditions of oxidative stress, the Nrf2-Keap1 complex is interrupted by inductors. Flavonoids act as inductors and are oxidized to its quinone derivatives. After, the corresponding quinone flavonoids form reacts in a Michael addition with Keap1. Nrf2 is released from Keap1, undergoes rapid translocation into the nucleus when bound to antioxidant response elements (AREs) and expresses phase II inducing cell detoxification and antioxidant proteins, such as hemoxygenase-1 (HO-1) and glutamate-L-cysteine ligase (GCLC) [35] (Figure 10). 


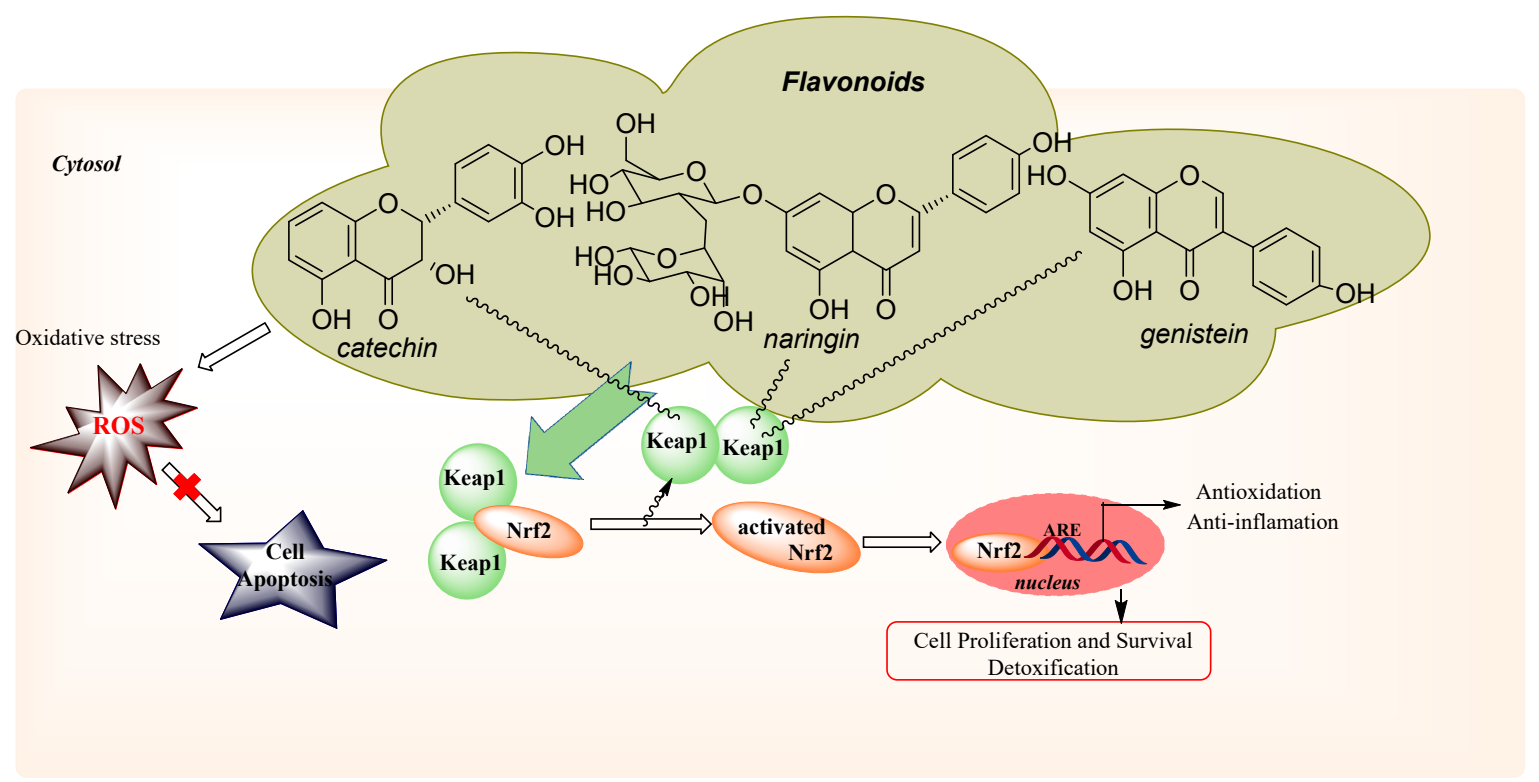

Figure 10. Schematic model representation of flavonoids mechanism involved in antioxidative defense.

\section{Materials and Methods}

\subsection{Romanian Basil Hybrid Plant Materials}

Two different selections of Romanian basil varieties named "Aromat de Buzau" (O. basilicum) and "Macedon" (O. citriodorum) were grown using organic production methods at the Vegetable Research and Development Station, Buzau, Romania. The mature plants used for the research investigation were harvested in early in August 2019.

\subsection{Sample Preparation}

The separation of chemical compounds, based on polarity, from plant tissue involves the use of selective solvents depending on the desired compounds [39]. The entire plants were dried at ambient temperature until the aerial parts became dried for grinding. After 3 weeks of drying, the basil plant materials (flower, seeds, and leaves) were ground using a mechanical blender into a fine powder. Methanol and ethanol were used as solvents for extraction of phytochemicals to obtain the maximum yield by using a reflux condenser. Subsequently, $10 \mathrm{~g}$ of basil powder and $100 \mathrm{~mL}$ of alcohol were added in a round bottom flask, and the samples were ultrasonicated for two hours. The resulted alcoholic extracts were filtered and concentrated in vacuum using a rotary evaporator to obtain the dry extract. The crude obtained extracts were stored at $-18{ }^{\circ} \mathrm{C}$ until further use. The extraction was performed in triplicate.

\subsection{Phytochemical characterization of the Romanian Varieties of Basil}

\subsubsection{Phenolic Acids content}

The total phenolic acids content was determined spectrophotometrically using Folin - Ciocalteu assay, according to the procedure described by Cudalbeanu, 2018 [23]. The Folin-Ciocalteu reagent reacts with phenolic compounds changing the color from yellow to blue. Briefly, $10 \mu \mathrm{L}$ of basil sample was added to $25 \mu \mathrm{L}$ of $1 \mathrm{~N}$ Folin-Ciocalteu reagent and allowed this mixture to stand for 5 min before adding $25 \mu \mathrm{L}$ of $20 \% \mathrm{Na}_{2} \mathrm{CO}_{3}$ aqueous solution. In the blank sample, the Folin-Ciocalteu reagent was replaced with alcohol. The absorbance value was measured versus the prepared blank at $760 \mathrm{~nm}$, after $30 \mathrm{~min}$ at room temperature, using a Tecan Pro 200 apparatus, Tecan Trading AG multiwell plate reader (Männedorf, Switzerland). The total phenolic acids content was expressed as mg of gallic acid equivalents per gram sample (mg GAEq/g extract) through a calibration curve with gallic acid, and mg 
of tannic acid equivalents per gram sample (mg TAEq/g extract) through a calibration curve with tannic acid, respectively.

\subsubsection{Flavonoids Content}

Briefly, $100 \mu \mathrm{L}$ of $2 \% \mathrm{AlCl}_{3}$ aqueous solution was added to $100 \mu \mathrm{L}$ of sample. The absorbance value was read at $415 \mathrm{~nm}$ using the Tecan Pro 200 multiwell plate reader. For the blank sample, the basil sample was replaced with appropriate solvent. Quercetin and rutin were used as reference standards, and the results are given in mg quercetin equivalents per $1 \mathrm{~g}$ of sample, and $\mathrm{mg}$ rutin equivalents per $1 \mathrm{~g}$ of sample, respectively $[23,40,41]$.

\subsection{Antioxidant Potentials of the Romanian Varieties of Basil}

\subsubsection{DPPH assay}

Briefly, $100 \mu \mathrm{L}$ of each basil sample was added to $100 \mu \mathrm{L}$ DPPH $(100 \mu \mathrm{g} / \mathrm{mL})$. The samples were kept at room temperature in the dark for 20,35, and $50 \mathrm{~min}$. The UV-Vis spectra were recorded using Tecan Pro 200 multiwell plate reader (Männedorf, Switzerland). The absorbance values were recorded at $517 \mathrm{~nm}$ for each sample, compared with a blank sample (without extract). The DPPH inhibition percent was calculated using the formula: $\%$ inhibition $=($ Abs blank - Abs sample $) /$ Abs blank $\times 100$. The $\mathrm{IC}_{50}$ values were graphically determined by plotting the inhibition percent against inhibitory concentration. The antioxidant activity index (AAI) was calculated using following formula: $\mathrm{AAI}=$ final $\mathrm{DPPH}$ concentration $/ \mathrm{IC}_{50}$ value $[23,42]$.

\subsubsection{Electrochemical Evaluation of Antioxidant Capacity by Cyclic Voltammetry}

The methanolic and ethanolic Romanian basil extracts were electrochemical evaluated using Biologic potentiostat/galvanostat SP-150 (Claix, France) at the room temperature. The electrochemical experiments were performed using an electrochemical cell with three electrodes: glass carbon electrode as working electrode, $\mathrm{Ag} / \mathrm{AgCl}$ sat $(\mathrm{E}=0.194 \mathrm{~V} / \mathrm{NHE})$ as reference electrode and $\mathrm{Pt}$ wire as counter electrode. The applied potential was $\mathrm{E}= \pm 1 \mathrm{~V}$ vs. $\mathrm{Ag} / \mathrm{AgClsat}$, with rate potential at $100 \mathrm{mVs}^{-1}$. The working electrode was polished with $\mathrm{BASi}{ }^{\circledR}$ polishing kit (alumina and diamond slurries) followed by washing with alcohol after each voltammetry experiment. Also, UV-Vis spectra were recorded for basil samples before and after cyclic voltammetry experiment, in the wavelength range from 200 to $500 \mathrm{~nm}$, using the SPECORD 210 PLUS double-beam 500 spectrophotometer (Analytik Jena, Jena, Germany) [36].

\subsection{HPLC-DAD Separation, Identification and Quantification of Flavonoid Compounds}

The HPLC-DAD (high-Performance Liquid Chromatography with Diode-Array Detector) analysis was carried out using a High-Performance Liquid Chromatography Systems L-3000 (RIGOL TECHNOLOGIES, INC Beijing, China). In the chromatographic analysis, the Kinetex EVO C18 (150 $4.6 \mathrm{~mm}$, particle size of $5 \mu \mathrm{m}$ ) column was used with an injection volume of $10 \mu \mathrm{L}$. The solvents used were (A) $0.1 \%$ trifluoroacetic acid (TFA) in water and (B) $0.1 \%$ trifluoroacetic acid (TFA) in acetonitrile. The gradient elution was from $2 \%$ to $100 \% \mathrm{~B}$ at $30{ }^{\circ} \mathrm{C}$ for $60 \mathrm{~min}$, and the elution flow was set at $1000 \mu \mathrm{L} / \mathrm{min}$. Further, $300 \mathrm{~nm}$ analytical wavelength was used for detection in accordance with the literature [42].

\subsection{Statistical Analysis}

Three extractions were performed for each sample, and all assays were replicated three times for each sample. All the data experiments were expressed as mean \pm standard deviation of the three independent assays. Data results were analyzed for statistical significance using the Microsoft Excel Program and Origin Pro 9.1. 


\section{Conclusions}

The continuous research carried out in the field of natural compounds with antioxidants properties contributes to knowledge concerning the availability of natural and healthy compounds from herbal plants, which are particularly more attractive for commercial food producers and consumers than the synthetic antioxidants.

The results obtained in our study indicated that alcoholic extracts of the Romanian varieties of basil had moderate to high total phenolic acid content and good antioxidant activity against free radical DPPH in vitro assays. An evident correlation was found between the antioxidant capacity and the total phenolic content, and also a good correlation has been observed between the antioxidant capacities measured by means of the two techniques (DPPH assay and Cyclic Voltammetry).

The Romanian basil variety "Aromat de Buzau" showed the highest antioxidant activity and the highest contents of phenolic acid compounds. The major flavonoid found in both basil varieties was naringin, compound known for its pharmacologic activity such as hepatoprotective, hypocholesterolemic and antitumoral. In conclusion, our results partly justify the traditional uses of basil, with both Romanian Ocimum varieties being recommended to be a good dietary source of flavonoids. To validate the benefits of Ocimum extracts for human health and also for pharmaceutical industry, further work is necessary, and we have already started toxicity studies.

Author Contributions: Conceptualization, F.B., M.C., B.F., and R.M.D.; methodology, F.B., M.C., B.F., R.M.D., and G.C., software, M.C.; M.D.I.M., F.B., and E.L.L.; formal analysis, F.B. and M.D.I.M., investigation, F.B., M.C., B.F., R.M.D., G.C., and S.M.A., resources, B.F., R.M.D., C.V., G.C., and S.M.A., data curation, F.B., M.C., B.F., R.M.D., and S.M.A.; writing - original draft preparation, F.B. and M.C.; writing-review and editing, F.B., M.C., B.F., R.M.D., and G.C. visualization, F.B., M.C., M.D.I.M., B.F., R.M.D., and E.L.L.; supervision, M.C., B.F., and R.M.D.; project administration R.M.D. and B.F.; funding acquisition, B.F., R.M.D., and C.V. All authors have read and agreed to the published version of the manuscript.

Funding: F.B. gratefully acknowledge the support obtained through the project "Excellence, performance, and competitiveness in the Research, Development, and Innovation activities at "Dunarea de Jos" University of Galati", acronym "EXPERT", financed by the Romanian Ministry of Research and Innovation in the framework of Programme 1-Development of the national research and development system, Sub-programme 1. 2-Institutional Performance-Projects for financing excellence in Research, Development and Innovation, Contract no. 14PFE/17.10.2018. S.M.A. gratefully acknowledge the support obtained through the project SusMAPWaste, SMIS104323, Contract No. 89/09.09.2016, from the Operational Program Competitiveness 2014-2020, project co financed from the European Regional Development Fund.

Acknowledgments: M.C. acknowledges the support of this work by the project ANTREPRENORDOC, in the framework of Human Resources Development Operational Programme 2014-2020, financed from the European Social Fund under the contract number 36355/23.05.2019 HRD OP/380/6/13-SMIS Code: 123847.

Conflicts of Interest: The authors declare no conflict of interest.

\section{References}

1. Chenni, M.; El Abed, D.; Rakotomanomana, N.; Fernandez, X.; Chemat, F. Comparative Study of Essential Oils Extracted from Egyptian Basil Leaves (Ocimum basilicum L.) Using Hydro-Distillation and Solvent-Free Microwave Extraction. Molecules 2016, 21, 113. [CrossRef] [PubMed]

2. Tangpao, T.; Chung, H.H.; Sommano, S.R. Aromatic Profiles of Essential Oils from Five Commonly Used Thai Basils. Foods 2018, 7, 175. [CrossRef] [PubMed]

3. Li, Y.R.; Li, G.H.; Zhou, M.X.; Xiang, L.; Ren, D.M.; Lou, H.X.; Wang, X.N.; Shen, T. Discovery of natural flavonoids as activators of Nrf2-mediated defense system. Bioorganic Med. Chem. 2018, 26, 5140-5150. [CrossRef] [PubMed]

4. Zhai, X.; Lin, M.; Zhang, F.; Hu, Y.; Xu, X.; Li, Y.; Liu, K.; Ma, X.; Tian, X.; Yao, J. Dietary flavonoid genistein induces Nrf2 and phase II detoxification gene expression via ERKs and PKC pathways and protects against oxidative stress in Caco-2 cells. Mol. Nutr. Food Res. 2013, 57, 249-259. [CrossRef] [PubMed]

5. Leonardo, C.C.; Doré, S. Dietary flavonoids are neuroprotective through Nrf2-coordinated induction of endogenous cytoprotective proteins. Nutr. Neurosci. 2011, 14, 226-236. [CrossRef] [PubMed]

6. Heo, H.J.; Kim, D.K.; Shin, S.C.; Kim, M.J.; Kim, B.Y.; Shin, D.G. Effect of Antioxidant Flavanone, Naringenin, from Citrus junos on Neuroprotection. J. Agric. Food Chem. 2004, 52, 1520-1525. [CrossRef] 
7. Mendonca, P.; Soliman, K.F.A. Flavonoids Activation of the Transcription Factor Nrf2 as a Hypothesis Approach for the Prevention and Modulation of SARS-CoV-2 Infection Severity. Antioxidants 2020, 9, 659. [CrossRef]

8. Alam, A.M.; Subhan, N.; Rahman, M.M.; Uddin, S.J.; Reza, H.M.; Sarker, S.D. Effect of Citrus Flavonoids, Naringin and Naringenin, on Metabolic Syndrome and Their Mechanisms of Action. American Society for Nutrition. Adv. Nutr. 2014, 5, 404-417. [CrossRef]

9. Yao, Q.; Lin, M.T.; Zhu, Y.D.; Xu, H.L.; Zhao, Y.Z. Recent Trends in Potential Therapeutic Applications of the Dietary Flavonoid Didymin. Molecules 2018, 23, 2547. [CrossRef]

10. Nijveldt, R.J.; van Nood, E.; van Hoorn, D.E.; Boelens, P.G.; van Norren, K.; van Leeuwen, P.A. Flavonoids: A review of probable mechanisms of action and potential applications. Am. J. Clin. Nutr. 2001, 74, 418-425. [CrossRef]

11. Julsing, M.K.; Koulman, A.; Woerdenbag, H.J.; Quax, W.J.; Kayser, O. Combinatorial biosynthesis of medicinal plant secondary metabolites. Biomol. Eng. 2006, 23, 265-279. [CrossRef] [PubMed]

12. Trantas, E.; Panopoulos, N.; Ververidis, F. Metabolic engineering of the complete pathway leading to heterologous biosynthesis of various flavonoids and stilbenoids in Saccharomyces cerevisiae. Metab. Eng. 2009, 11, 355-366. [CrossRef] [PubMed]

13. Agic, D.; Brkic, H.; Tomic, S.; Karacic, Z.; Spoljarevic, M.; Lisjak, M.; Beslo, D.; Abramic, M. Validation of flavonoids as potential dipeptidyl peptidase III inhibitors: Experimental and computational approach. Chem. Biol. Drug Des. 2017, 89, 619-627. [CrossRef] [PubMed]

14. Masek, A.; Chrzescijanska, E.; Latos, M.; Zaborski, M. Influence of hydroxyl substitution on flavanone antioxidants properties. Food Chem. 2016. [CrossRef]

15. Kapoor, R.; Sirohi, V.K.; Gupta, K.; Dwivedi, A. Naringenin ameliorates progression of endometriosis by modulating Nrf2/Keap1/HO1 axis and inducing apoptosis in rats. J. Nutr. Biochem. 2019, 70, 215-226. [CrossRef]

16. Naeini, F.; Namkhah, Z.; Ostadrahimi, A.; Tutunchi, H.; Hosseinzadeh-Attar, M.J. A Comprehensive Systematic Review of the Effects of Naringenin, a Citrus-Derived Flavonoid, on Risk Factors for Nonalcoholic Fatty Liver Disease. Am. Soc. Nutr. 2020, 1-16. [CrossRef]

17. Zhao, L.; Wang, Y.; Liu, J.; Wang, K.; Guo, X.X.; Ji, B.; Wu, W.; Zhou, F. Protective Effects of Genistein and Puerarin against Chronic Alcohol-Induced Liver Injury in Mice via Antioxidant, Anti-Inflammatory, and Anti-Apoptotic Mechanisms. J. Agric. Food Chem. 2016, 2-31. [CrossRef]

18. Hakkim, F.L.; Arivazhagan, G.; Boopathy, R. Antioxidant property of selected Ocimum species and their secondary metabolite content. J. Med. Plants Res. 2008, 2, 250-257.

19. Purushothaman, B.; Srinivasan, R.P.; Suganthi, P.; Ranganathan, B.; Gimbun, J.; Shanmugam, K. A Comprehensive Review on Ocimumbasilicum. J. Nat. Remedies 2018, 18, 71-85. [CrossRef]

20. Vînătoru, C.; MușatZamfir, B.; Bratu, C.; Peticilă, A. Results and perspectives in Ocimumbasilicum (basil) breeding at vegetable research and development station Buzău. Horticulture 2019, LXIII, 161-168.

21. Falowo, A.B.; Mukumbo, F.E.; Idamokoro, E.M.; Afolayan, A.J.; Muchenje, V. Phytochemical Constituents and Antioxidant Activity of Sweet Basil (Ocimumbasilicum L.) Essential Oil on Ground Beef from Boran and Nguni Cattle. Hindawi Int. J. Food Sci. 2019, 1-8. [CrossRef]

22. Majdi, C.; Pereira, C.; Dias, M.I.; Calhelha, R.C.; Alves, M.J.; Rhourri-Frih, B.; Charrouf, Z.; Barros, L.; Amaral, J.S.; Ferreira, I.C.F.R. Phytochemical Characterization and Bioactive Properties of Cinnamon Basil (Ocimum basilicum cv. 'Cinnamon') and Lemon Basil (Ocimum x citriodorum). Antioxidants 2020, 9, 369. [CrossRef] [PubMed]

23. Mohsen, S.M.; Ammar, A.S.M. Total phenolic contents and antioxidant activity of corn tassel extracts. Food Chem. 2009, 112, 595-598. [CrossRef]

24. Chiva-Blanch, G.; Badimon, L. Effects of Polyphenol Intake on Metabolic Syndrome: Current Evidences from Human Trials. Oxidative Med. Cell. Longev. 2017. [CrossRef] [PubMed]

25. Al-Jaber, N.A.; Awaad, A.S.; Moses, J.E. Review on some antioxidant plants growing in Arab world. J. Saudi Chem. Soc. 2011, 15, 293-307. [CrossRef]

26. Cudalbeanu, M.; Furdui, B.; Cârâc, G.; Barbu, V.; Iancu, A.V.; Marques, F.; Leitão, J.H.; Sousa, S.A.; Dinica, R.M. Antifungal, Antitumoral and Antioxidant Potential of the Danube Delta Nymphaea alba Extracts. Antibiotics 2020, 9, 7. [CrossRef] 
27. Fan, R.; Huang, X.; Wang, Y.; Chen, X.; Ren, P.; Ji, H.; Xie, Y.; Zhang, Y.; Huang, W.; Qiu, X.; et al. Ethnopharmacokinetic- and Activity-Guided Isolation of a New Antidepressive Compound from Fructus Aurantii Found in the Traditional Chinese Medicine Chaihu-Shugan-San: A NewApproach and Its Application. Evid.-Based Complement. Altern. Med. 2012,1-8. [CrossRef]

28. Wu, M.H.; Zhu, L.; Zhou, Z.Z.; Zhang, Y.Q. Coimmobilization of Naringinases on Silk Fibroin Nanoparticles and Its Application in Food Packaging. J. Nanoparticles 2013, 1-6. [CrossRef]

29. Castronuovo, D.; Russo, D.; Libonati, R.; Faraone, I.; Candido, V.; Picuno, P.; Andrade, P.; Valentao, P.; Milella, L. Influence of shading treatment on yield, morphological traits and phenolic profile of sweet basil (Ocimum basilicum L.). Sci. Hortic. 2019, 254, 91-98. [CrossRef]

30. Dah-Nouvlessounon, D.; Adjanohoun, A.; Sina, H.; Noumavo, P.A.; Diarrasouba, N.; Parkouda, C.; Madodé, Y.E.; Dicko, M.H.; Baba-Moussa, L. Nutritional and Anti-Nutrient Composition of Three Kola Nuts (Cola nitida, Cola acuminata and Garcinia kola) Produced in Benin. Food Nutr. Sci. 2015, 6, 1395-1407. [CrossRef]

31. Wanga, Y.; Gao, Y.; Ding, H.; Liu, S.; Han, X.; Gui, J.; Liu, D. Subcritical ethanol extraction of flavonoids from Moringa oleifera leaf and evaluation of antioxidant activity. Food Chem. 2017, 218, 152-158. [CrossRef] [PubMed]

32. Scherer, R.; Godoy, H.T. Antioxidant activity index (AAI) by the 2,2-diphenyl-1-picrylhydrazyl method. Food Chem. 2009, 112, 654-658. [CrossRef]

33. Gil, E.S.; Couto, R.O. Flavonoid electrochemistry: A review on the electroanalytical applications. Rev. Bras. Farmacogn. Braz. J. Pharmacogn. 2013, 23, 542-558. [CrossRef]

34. Olszowy, M. What is responsible for antioxidant properties of polyphenolic compounds from plants? Plant Physiol. Biochem. 2019, 144, 135-143. [CrossRef] [PubMed]

35. Kumar, H.; Kim, I.S.; More, S.V.; Kim, B.W.; Choi, D.K. Natural product-derived pharmacological modulators of Nrf2/ARE pathway for chronic diseases. Nat. Prod. Rep. 2013. [CrossRef] [PubMed]

36. Zhang, T.; Wang, F.; Xu, H.X.; Yi, L.; Qin, Y.; Chang, H.; Mi, M.T.; Zhang, Q.Y. Activation of nuclear factor erythroid 2-related factor 2 and PPAR $\gamma$ plays a role in the genistein-mediated attenuation of oxidative stress-induced endothelial cell injury. Br. J. Nutr. 2013, 109, 223-235. [CrossRef] [PubMed]

37. Lou, H.; Jing, X.; Wei, X.; Shi, H.; Ren, D.; Zhang, X. Naringenin protects against 6-OHDA-induced neurotoxicity via activation of the Nrf2/ARE signaling pathway. Neuropharmacology 2014, 79, 380-388. [CrossRef] [PubMed]

38. Tseng, Y.T.; Hsu, H.T.; Lee, T.Y.; Chang, W.H.; Lo, Y.C. Naringenin, a dietary flavanone, enhances insulin-like growth factor 1 receptor-mediated antioxidant defense and attenuates methylglyoxal-induced neurite damage and apoptotic death. Nutr. Neurosci. 2019, 1-12. [CrossRef] [PubMed]

39. Abin, K.; Arjunan, M.K.; Binu, T.; Delse, P.S.; Satheesh, G. Effect of extraction solvents on phytochemicals of various parts of Salacia fruticosa Wall. (Celastraceae)-An endemic medicinal plant. World Wide J. Multidiscip. Res. Dev. 2017, 3, 108-115.

40. Dah-Nouvlessounon, D.; Adjanohoun-Sagbadja, H.; Diarrasouba, N.; Sina, H.; Noumavo, P.A.; Baba-Moussa, F.; Adjanohoun, A.; Gbenou, J.D.; Baba-Moussa, L. Antimicrobial, Antioxidant, Cytotoxic Activities and Phytochemical Assessment of Cola acuminata used in Benin. Int. J. Pharm. Pharm. Sci. 2015, 7, 102-109.

41. Jing, L.; Ma, H.; Fan, P.; Gao, R.; Jia, Z. Antioxidant potential, total phenolic and total flavonoid contents of Rhododendron anthopogonoides and its protective effect on hypoxia-induced injury in PC12 cells. BMC Complement Altern Med. 2015, 15, 287. [CrossRef] [PubMed]

42. Chokki, M.; Cudălbeanu, M.; Zongo, C.; Dah-Nouvlessounon, D.; Ghinea, I.O.; Furdui, B.; Raclea, R.; Savadogo, A.; Baba-Moussa, L.; Avramescu, S.M.; et al. Exploring Antioxidant and Enzymes (A-Amylase and B-Glucosidase) Inhibitory Activity of Morinda lucida and Momordica charantia Leaves from Benin. Foods 2020, 9, 434. [CrossRef] [PubMed]

Sample Availability: Samples of the compounds are not available from the authors.

(C) 2020 by the authors. Licensee MDPI, Basel, Switzerland. This article is an open access article distributed under the terms and conditions of the Creative Commons Attribution (CC BY) license (http://creativecommons.org/licenses/by/4.0/). 